\title{
Philosophiques
}

Christian Atias, Savoir des juges et savoir des juristes. Mes

premiers regards sur la culture juridique québécoise, Montréal, Centre de recherche en droit privé et comparé du Québec, 1990.

\section{Robert Hébert}

Volume 19, numéro 1, printemps 1992

URI : https://id.erudit.org/iderudit/027176ar

DOI : https://doi.org/10.7202/027176ar

Aller au sommaire du numéro

Éditeur(s)

Société de philosophie du Québec

ISSN

0316-2923 (imprimé)

1492-1391 (numérique)

Découvrir la revue

Citer cet article

Hébert, R. (1992). Christian Atias, Savoir des juges et savoir des juristes. Mes premiers regards sur la culture juridique québécoise, Montréal, Centre de recherche en droit privé et comparé du Québec, 1990. Philosophiques, 19(1), 123-129. https://doi.org/10.7202/027176ar d'utilisation que vous pouvez consulter en ligne.

https://apropos.erudit.org/fr/usagers/politique-dutilisation/ 
CHRISTIAN ATIAS, Savoir des juges et savoir des juristes. Mes premiers regards sur la culture juridique québécoise, Montréal, Centre de recherche en droit privé et comparé du Québec, 1990.

\section{par Robert Hébert}

D'aucuns le savent: il existe depuis quinze ans dans la province de Québec une extraordinaire renaissance intellectuelle, renaissance qui ne passe plus par les chemins de la littérature ou des sciences humaines, encore moins par la philosophie officielle, suffisante bien que frileuse à son stade olympique, mais par la recherche et l'enseignement du droit. Plusieurs facteurs expliquent cette renaissance. Ce n'est pas le lieu ici de développer d'autant plus que cette pensée juridique qui renaît, produit et $s$ 'écrit n'est pas incompatible avec une certaine crise de fond "sociétale", comme nous le verrons peut-être au prochain Sommet de la Justice, en février 1992, à l'heure où le nouveau Code civil vient d'être adopté, non sans pénibles contorsions.

À cela s'ajoute une dimension de longue durée qui détermine les conditions globales et quotidiennes de la recherche du droit: contrairement aux neuf autres provinces du Canada, le droit québécois est un droit mixte dont la source événementielle est la Cession diplomatique de l'an 1763. En gros, depuis l'Acte de Québec (1774) qui réservait le "property and civil rights" à la coutume de Paris jusqu'à l'entreprise du Code civil du Bas-Canada (1866) inspiré du Code Napoléon de 1804 et incorporé à l'AANB. Droit civil de la famille romano-germanique greffé sur une common law qui l'a marqué par la procédure, enclavé à l'intérieur d'un droit public et d'un droit criminel anglais ${ }^{1}$. Cette particularité de mixture se retrouve aussi en Louisiane, en Écosse, en Afrique du Sud; autrement aux Philippines, au Ceylan, à Porto-Rico. Fascinés, beaucoup d'observateurs et de juristes étrangers ont travaillé là certaines problématiques classiques de droit comparé (réception du droit étranger, "legal transplants", histoire des administrations coloniales...). Ce métissage juridique, civilisé (pour ne pas parler de l'autre en Nouvelle-France, joyeusement sauvage) est donc une pratique vieille de deux siècles et quart.

C'est de ces grandes eaux qu'émerge un livre extrêment stimulant de Christian Atias, professeur à l'Université d'Aix-Marseille et avocat à la Cour d'appel d'Aixen-Provence, Boulton Senior Fellow de l'Université 
McGill. En 1987, cet ouvrage était annoncé comme paru sous le titre suivant: Premiers regards sur la culture juridique québécoise. Je me suis mis sur la piste d'autant que je m'intéressais au procès Guibord (1870: entre droit canonique, intégrisme et premier Code civil) et que la culture juridique des hommes du XIXe siècle m'interrogeait, celle par exemple de Maximilien Bibaud, auteur d'un Essai de logique judiciaire (1852) ou de l'avocat Joseph Doutre. En fait le livre est paru l'année dernière sous un titre plus explicite. De quoi s'agit-il donc? Atias est le promoteur en France, "en contemplation du seul droit français", de ce qu'il appelle l'épistémologie juridique descriptive dont l'objet est la connaissance du droit en tant qu'elle diffère de celle du législateur et du juge. Elle tend à décrire les attitudes intellectuelles de ceux et celles qui sont censés connaître le droit (notaires, avocats, professeurs de droit, auteurs de doctrine...) et espère approfondir l'analyse du raisonnement juridique qui ultimement concerne le juste. Dans la mesure où le droit québécois dans son ensemble fait cohabiter droit civil codifié et common law, les hiérarchies des sources du droit se renversent elles-mêmes, les traditions savantes ne s'orientent plus de la même manière. Atias voit là un test, une épreuve pour ses hypothèses. Qu'est-ce que l'épistémologie juridique descriptive peut apporter à ceux et celles qui s'accupent du droit?

L'ouvrage est divisé en trois chapitres. Le premier chapitre "Une certaine image de la culture juridique québécoise " remplit près de la moitié et donne le motif stratégique de l'auteur: une fine analyse des avatars de l'adage anglais "our judges are our jurists". Contre les témoignages québécois qui se plaignent d'un manque de doctrine et de théories juridiques, contre un " auto-scepticisme intellectuel ", Atias veut revenir à l'origine de cet adage, ce symbole chargé de significations auréolées mais nébuleuses. À première vue, l'adage s'identifie à la common law, judge-made law par excellence, et ne serait que le corollaire de la règle du précédent; cependant il faut relativiser parce que la common law n'a jamais méconnu l'influence des rapporteurs, des grands commentateurs. Au fond, la traduction canadienne-française " nos juges sont nos juristes " depuis l'époque militante d'un juge Mignault - rappelons que ce demier fut professeur de droit à l'Université McGill avant sa nomination à la Cour Suprême du Canada en 1918 - et autres est essentiellement le symbole d'une culture sur la défensive, historiquement conglomérée à son corps défendant. Sans trop s'arrêter là-dessus, sans vouloir recenser trahisons et déviations, Atias préfère penser cette culture originale québécoise en rappellant le génie propre du droit civil, génie qui - à l'opposé du génie inductif anglais - tient à la cohérence interne et à la synthèse normative qu'il permet d'opérer avec un même code. Suit alors, sur le mode d'une mimésis argumentée, une double interprétation de ce symbole qui en démontre l'ambiguiité. Dans une interprétation positiviste, la formule "nos juges sont nos juristes" renvoie au pouvoir institutionnel des juges. C'est parce qu'il agit comme détenteur de l'autorité judiciaire et dans l'exercice de ses fonctions que le 
juge exprimerait nécessairement le droit. Il n'y aurait rien d'autre que les juges qui donneraient une réponse décisive, unique à chaque cas-litige. Dans une interprétation non-positiviste cependant, le droit n'est intéressant que pour ses justifications. L'autorité d'une décision tient à la qualité de l'argumentation étayée par les juges, à leur capacité de bien exposer une ratio decidendi; par exemple, et malgré le débat, la publication des opinions dissidentes sur le banc peut faire progresser la justice dans une meilleure compréhension des questions-litiges. Le juge ici serait au moins également juriste.

Porte-étendard flottant à tout vent, le symbole doit amener à la connaissance du droit dans sa réalité. Somme toute, les juristes n'ont pas à souffrir d'un complexe d'inutilité! Le deuxième chapitre donne les grandes lignes de l'épistémologie juridique fondée sur la distinction capitale entre savoir judiciaire et savoir juridique. Distinction qui ne répète pas celle de connaissance inférieure/supérieure ni rupture de type connaissance immédiate-commune/scientifique. En fait, juges et juristes ont des fonctions respectives. $D^{\prime}$ une part, le juge dit le droit (dicere jus) dans des conditions procédurales précises où il est en position de tiers impartial; la controverse judiciaire aboutit à une décision exécutoire; en l'espèce, elle doit se terminer; la nature du procès et la prohibition du déni de justice l'imposent. D'autre part, la controverse juridique parle du droit pour des espèces à venir; elle est interminable, fait proliférer anciennes notions et nouveaux problèmes, et le temps participe à la qualité de la réflexion théorique. Juges et juristes, avec leur formations intellectuelles, leurs spécialités, leurs convictions sociales travaillent, critiquent, argumentent ensemble, maintiennent la recherche du juste à l'intérieur du droit. Le savoir juridique forme donc un ordre savant traditionnel pour lequel Atias développe une sorte de phénoménologie de la sédimentation via le langage juridique. Tous les mots-clés du langage juridique sont indéfiniment ouverts, et déjà transportés par l'histoire économique et politique, la sociologie, les techno-sciences, la littérature, la philosophie.

Enfin, le troisième chapitre est une enquête sur l'argumentation juridique au Québec à partir d'un corpus de 108 décisions rendues par la Cour d'Appel en 1985. Après tant d'autres, Atias est frappé par le style des jugements. Contrairement aux juges français - non recrutés parmi les membres d'un barreau comme au Canada -, magistrats de carrière qui livrent des arrêts uniformes et sobres, les juges québécois pratiquent le ton personnel, découvitent plus leur opinion que l'argument lié à des principes, complexifient leur leçon. À l'anglaise, ils citent davantage la jurisrudence que la doctrine, étalent mème dangereusement leurs doutes, (leur patinage hybride entre common law et tradition civiliste) et s'adonnent à l'art périlleux de la re-définition. Suit alors une analyse comparative du rôle et de la portée des définitions légales. En conclusion, un peu abrupte: la mission des juges et juristes en Amérique du Nord comme partout 
ailleurs est de sauvegarder une culture juridique, à cette condition expresse que l'on distingue les uns des autres.

Voilà, je crains de ne pas donner ici un juste aperçu sur la richesse interne de l'ouvrage où il est mentionné, cité, discuté parfois de Kant, Bergson, Bachelard, Meyerson, Kuhn, Kalinowski, Hayek, Ricœur sans oublier une foule de juristes anglo-américains et français... Ne prétendant pas à la critique politique ni même au statut ancillaire d'une science, l'épistémologie juridique rebrasse autrement la question des sources du droit: législation, doctrine, jurisprudence - qu'Atias appelle plus précisément sources d'information sur le droit. Parfait. Ma seule réserve concerne l'arrière-plan canadien de cet adage "nos juges sont nos juristes" qui en fournit le prétexte et le sous-titre. La période à laquelle il est fait allusion est celle des années 1920/1930. Une entre-deux Guerres troublée par la récession économique et le renouveau nationaliste avant et après le statut de Westminster, avec déjà des mœurs américaines et où par ailleurs les rapports entre la France et le Canada français étaient plus ou moins "normalisés" (exotisme culturel et politique, archives, échanges académiques...), ne serait-ce qu'à l'occasion du bestseller anamnésique Maria Chapdelaine, réimprimé à Paris en 1921. Atias ne fait pas cette histoire sociale des idées ni ne mentionne que la question du pouvoir des juges était un topos classique à cette époque, comme on peut le voir avec le livre toujours en circulation de Mr. Justice Cardozo (The Nature of the Judicial Process, New Haven, Yale Univ. Press, 1921), faisant même le pont avec les juristes continentaux Gény et Ehrlich. Il est étonnant qu'il ne fasse pas aussi le lien avec Antoinette Maurin, Le rôle créateur du juge dans les jurisprudences canadienne et française comparées, Paris, A. Rousseau, 1938 - publiée il y a cinquante ans dans la collection de l'Institut de droit comparé (Paris) dirigée par Lévy-Ullmann qui avait déjà écrit spécialement pour la québécoise Revue du droit un article intitulé "De l'utilité des études comparatives", I (mai 1923), pp. 385-398. Revue importante à dépouiller systématiquement pour y décoder les tensions entre les "intégristes" du Code civil et de l'âme canadienne-française de la vieille France, les philosophes néothomistes qui s'aventuraient dans le droit naturel via le droit canonique et les esprits libéraux ouverts aux législations sociales (syndicats, municipalités, assurances, épineuse question du divorce) et donc au droit dit statutaire.

Allons plus loin. La cyclothymique (je préfère ce terme médical à celui de "dialectique ") optimisme/pessimisme entourant la valeur du Code civil s'expose là où on attendrait le moins de détails: un souvenir atlantique en porte-à-faux. Nos juristes sont plutôt prudes sur la chose. Mises à part les festivités diplomatiques et sentimentales du 400e anniversaire de la découverte du Canada par Jacques Cartier où la France via le Comité France-Amérique avait délégué "ses plus éminents juristes, messieurs Capitant, Josserand et Demogue » 
à l'occasion des Journées du Droit civil Français (cf. Livre-souvenir..., Montréal-Paris, Barreau de Montréal et Librairie du Recueil Sirey, 1936), il faut dépouiller le monumental deuxième Congrès de la langue française, entre autres les Mémoires, t. II, Québec, Action catholique, 1938. Le programme est impressionnant: Demogue de l'Université de Paris, Perrault, Tellier sur l'esprit français (dans la jurisprudence, le droit commercial, le droit municipal), La Durantaye, juge FabreSurveyer, Morin sur les difficultés de la langue française (textes législatifs, plaidoiries...), Mignault sur la «Méthode d'interprétation de nos lois (stare decisis) ", sept communications sur le statut juridique du français au Canada, en Louisiane et en Nouvelle-Angleterre, juge Rivard sur la dualité de la législation (empiètements, dangers)... Dans la liste des vœux adoptés en assemblée générale, on peut lire ceci: "Que dans l'interprétation de nos lois, les décisions de nos tribunaux reconnaissent le système juridique français basé sur la doctrine et refusent aux arrêts une importance prépondérante et une autorité décisive". Étonnant malentendu, la doctrine n'ayant jamais ce poids décisif en France! Il y aurait tout un travail à faire sur ce militantisme exotique. Or donc, au mois d'août 1939, s'ouvrait à Québec et à Montréal le Premier Congrès international de l'Association Henri Capitant pour la culture juridique française, Montréal, Imprimerie Desmarais, 1940; entre la Grèce, Haïti, Liban et Syrie, Japon, Pologne, Yougoslavie et l'Hexagone élargie, six grandes contributions au nom du Canada (Province de Québec): dans la section "De l'abus du droit dans la responsabilité ", Mlle Maurin à côté de l'ancien juge Mignault alors âgé de 85 ans!

Christian Atias semble opérer un transfert de mission des épaules du juge aux épaules du juriste en forçant une distinction essentielle mais néanmoins surannée. Est-ce un même et autre enjeu historique, à son tour de rôle? Dans la wilderness bas-canadienne 1920/1930, nos avocats-et-juges-également-juristes chevauchaient tradition continentale et common law ayant conscience a distance que les vieilles perruques du Conseil privé de Londres détenaient l'ultime clé de leur interprétation. Mais ce sont eux qui ont aussi accéléré la souveraineté judiciaire du Canada, définitivement acquise en 1949! Aucun juriste français ou américain n'a pu expérimenter cela en connaissance de cause. Écrivant et pensant comme des législateurs, ils cherchaient des alliés pour contrer l'indicible rapport de forces en deçà du droit'. Dans la bibliothèque, au prétoire, dans l'aréna politico-culturel, ils étaient la réponse contemporaine " canadienne ou québécoise" au topos sociologique du pouvoir des juges; ils constituaient l'épine dorsale et l'épistémologie vivante du droit moins comparé que comparant.

Mise à part cette réserve qui n'est pas de fond mais d'information et de forme quasi cinématographique, Savoir des juges et savoir des juristes. Mes premiers regards sur la culture juridique québécoise est un ouvrage inspirant, rempli d'idées, participant à cette renaissance 
intellectuelle dont je parlais au début. Effervescence contemporaine d'ailleurs, tant en France qu'aux États-Unis bien que les enjeux ou les combats théoriques prennent une figure très différente ${ }^{3}$. Je ne sais pas comment civilistes bilingues et common lawyers vont recevoir ou voudront bien se servir de cette contribution à la connaissance du droit. Mais à bien des égards, il renforce ma conviction qu'il serait extrêmement utile, intéressant voire agréable pour la "clientèle " cégépienne d'introduire dans le curriculum philosophique des éléments de philosophie du droit et de la jurisprudence, à partir des travaux, des publications de tous les juristes œuvrant au Québec. La qualité de la réflexion juridique dans les revues académique ou celles des barreaux est étonnante. Et quoi de plus vivifiant pour l'esprit qu'un bon commentaire d'arrêt, à partir d'un litige un peu "surréaliste". Quoi de plus territorial, déterminé et déterminant que la pensée d'un droit commun dans un espace que l'on souhaite civil. Logique, théorie de la définition et de l'argumentation, histoire des idées, philosophie de la culture, éthique, philosophie politique, ces domaines de travail pourraient recevoir une inflexion juridique qui est absente au collégial, en fait, même dans le programme des Techniques auxiliaires de la Justice, étrangement axées sur les matières criminelles et l'organisation tic au tac de la police.

Je ne sais trop quelle philosophie du droit l'usage d'une épistémologie juridique descriptive pourrait promouvoir à l'université, mis à part un retour aux sources standards des méthodes, analytiques et continentales. La philosophie officielle pourra-elle un jour nous éclairer sur la chose? Dans la province de Québec, la renaissance intellectuelle via le chemin obligé du Droit a été saisie tout d'abord par les sociologues. Rien de plus significatif que la confession voilée de Guy Rocher, depuis longtemps près des officines des institutions et de l'État, "Le sociologue et la sociologie dans l'administration publique et l'exercice du pouvoir politique ", Sociologie et sociétés, XII (octobre 1980), p. 45-63. Comme les sociologues ont détrôné les philosophes scolastico-thomistes dans l'aggiornamento de Vatican II et de la Révolution tranquille, ainsi les juristes et conseillers juridiques déclasseraient les sociologues de l'après-Référendum? Je lance l'idée. Mais les guerres frontalières de départements (criminologie, science politique, sociologie) face à l'empire du Droit nous laissent sur notre faim. Nous n'avons pas encore une sociologie historique du droit qui créerait au nord du $45 \mathrm{e}$ parallèle ses concepts et ses catégories à l'intérieur d'une philosophie du droit mixte. Ou d'une philosophie hybride du droit, dernière énigme d'une culture philosophique québécoise, notre marque de commerce? Entretemps, il est reposant de faire son miel avec les premiers numéros spéciaux de McGill Law Journal sur l'histoire du droit au Québec $\left(32, n^{\circ} 3,1987\right)$ et Anthropologie et sociétés sur le pluralisme juridique des cultures $\left(13, \mathrm{n}^{\circ} 1,1989\right)$ - cf. l'article de David Howes "La domestication de la pensée juridique québécoise " dont la généralisation des hypothèses (à partir de l'anthropologue 
Jack Goody et du cas québécois) devrait piquer les civilistes de tous pays et de toutes nationalités.

Département de Philosophie

Collège de Maisonneuve

\section{NOTES}

1. Louis Beaudoin, juriste français professeur à l'Université McGill depuis 1947, "La réception du droit étranger en droit privé québécois ", in Quelques aspects du droit de la province de Québec, préf. de Julliot de la Morandière, Paris, Éditions Cujas, 1963, pp. 3-70. Surtout l'introduction énergique de Maurice Tancelin à F. P. Walton, Le domaine et l'interprétation du Code civil du Bas-Canada (1904), Toronto, Butterworths, 1980, "Comment un droit peut-il être mixte?", pp. 1-33 avec une épigraphe de Montesquieu «Comment peut-on être Persan?". Dans une direction un peu différente, cf. R. A. Macdonald, "Understanding Civil Law Scholarship in Quebec », Osgoode Hall Law Journal, 23 (1985), pp. 573-608.

2. Relire les éclatantes interventions « whig " (anti-tradition politicojuridique française) de Edmund Burke au Bill de Québec (1774), sans oublier l'interprétation philosophique de la Conquête par Raynal, cf. mon anthologie, L'Amérique française devant l'opinion étrangère 1756-1960, Montréal, Hexagone, 1989. Nos juristes avaient peut-être traduit et annoté avec ironie le grand juriste Sir Frederick Pollock, The Genius of the Common Law, New York, Columbia University Press, 1912, ch. VI " Alliance and Conquest".

3. Cf. Christian Atias, «Culture juridique américaine et ordre savant traditionnel ", Revue Juridique Thémis, 20 (1986), pp. 149-167; dans la mesure où il traduit ses découvertes et sa recherche, compléter avec l'autre son de cloche effrayé de M. Krauss, " Nihilisme et interprétation des lois ", ibid., pp. 125-134, qui témoigne de la pénétration et de l'expansion polymorphe du derridisme aux USA. A quand l'équivalent québécois de la floridienne revue Law and Philosophy fondée en 1981 et imprimée aux Pays-Bas? 